\title{
Quality assessment of 'Fuyu' persimmon treated by a combination of $\gamma$-irradiation and 1-methylcyclopropene
}

\author{
Gwang Hwan Ahn ${ }^{1}$, Seong-Jin Choi ${ }^{2}$, Gye Hwa Shin ${ }^{3}$, Jun Tae Kim ${ }^{4 *}$ \\ ${ }^{1}$ Sweet Persimmon Research Institute, Gimhae 50871, Korea \\ ${ }^{2}$ Department of Biotechnology, Daegu Catholic University, Gyeongsan 38430, Korea \\ ${ }^{3}$ Department of Food and Nutrition, Kunsan National University, Gunsan 54150, Korea \\ ${ }^{4}$ Department of Food Science and Technology, Keimyung University, Daegu 42601, Korea
}

\begin{abstract}
As an alternative to chemical fumigation using reagents such as methyl bromide, sweet persimmon was treated with $\gamma$-irradiation with the aim of extending the export of persimmon to countries with strict quarantine requirements. 1-Methylcyclopropene (1-MCP) was also employed to prevent the loss of persimmon quality, as treatment by $\mathrm{\gamma}$ -irradiation can cause changes in the firmness and color of the fruit, in addition to physiological injuries. The persimmon quality was assessed at $25^{\circ} \mathrm{C}$ over a defined period of retail display following long term cold storage for 60 and 90 day. The persimmon firmness was significantly $(p<0.05)$ decreased following $\gamma$-irradiation and display at $25^{\circ} \mathrm{C}$ over 2 day, but was dramatically reduced after 3 day display and 60 day cold storage. Although irradiation increased the respiration rate of persimmon after long term storage, it was not significantly $(p>0.05)$ altered at the doses employed herein. In contrast, 1-MCP treatment significantly $(p<0.05)$ improved the persimmon firmness from 1.1 $\mathrm{N}$ to 6.0-20.6 $\mathrm{N}$ after $\mathrm{\gamma}$-irradiation treatment and 3 day display and little change in the skin color was observed compared to the untreated samples. The rate of flesh softening was also significantly reduced following 1-MCP treatment.
\end{abstract}

Key words : sweet persimmon, 8 -irradiation, 1-methylcyclopropylene, quality assessment

\section{Introduction}

Although the amount of exported Korean sweet persimmon has shown a steady increase in recent years, the importing countries have been limited to Southeast Asian countries such as Malaysia, Singapore, Hong Kong, Thailand, and Vietnam, due to the tighter quarantine processes in the United States of America and in European countries. Indeed, persimmon fruits are host to various quarantined pests including the persimmon fruit worm, the light brown apple moth, the long-tailed mealy bug, archips breviplicanus, and monema flavescens, which limit fruit export and marketability (1). Thus, to expand the export regions of persimmon fruit, the

*Corresponding author. E-mail : jtkim92@kmu.ac.kr Phone : 82-53-580-5171, Fax : 82-53-580-5372

Received 8 March 2018; Revised 12 June 2018; Accepted 18 June 2018.

Copyright (c) The Korean Society of Food Preservation. All rights reserved. quarantine requirements of the various countries must be satisfied. To achieve this, fumigation (e.g., methyl bromide), extreme temperatures, the use of controlled atmospheres, irradiation, and combinations of the above are commonly employed (2). More specifically, methyl bromide $\left(\mathrm{CH}_{3} \mathrm{Br}\right)$ treatment is often used for pest control because it has a wide spectrum of activity (3). However, an eco-friendly replacement for methyl bromide was necessary due to its phase-out requirements outlined in the 1987 Montreal Protocol on Ozone Depleting Substances (4).

In addition, irradiation is an effective and eco-friendly non-chemical treatment for the eradication of harmful insects in fruits and vegetables $(5,6)$. It has been also suggested that ionizing irradiation could be employed to sterilize or kill pests without damaging the flowers (7), with $\gamma$-irradiation doses $<1 \mathrm{kGy}$ being permitted for treating the majority of fresh fruits and vegetables (8). However, high doses of radiation can promote the softening of persimmon fruits, which renders them undesirable and unmarketable. 
To retain the quality of persimmon fruit following treatment with $\gamma$-irradiation, a combined technique based on the use of 1-methylcyclopropene (1-MCP) could be employed, as this prevents ethylene-dependent responses, such as the softening and senescence of fruits and vegetables (9). 1-MCP is structurally similar to ethylene, and so it binds irreversibly to the ethylene receptors of persimmon, and has great potential in terms of delaying softening and extending product shelf-life $(9,10)$. Indeed, the effect of 1-MCP in delaying ripening and softening has been studied in a number of fruits, including guava, apple, cherimoya, pear, mangosteen, plum, and avocado (11-16).

Thus, we herein report the use of $\mathrm{y}$-irradiation for the treatment of sweet persimmon with doses of $0,200,400$, 600 , and $800 \mathrm{~Gy}$. Changes in the persimmon quality following $\gamma$-irradiation and treatment with 1-MCP are investigated by measuring the firmness, respiration rate, color change, and physiological injuries following storage.

\section{Materials and methods}

\section{Materials}

'Fuyu' persimmon fruit, freshly harvested from a farm in Changwon, Korea, was purchased and transported to a chilled storage unit at $0^{\circ} \mathrm{C}$ prior to treatment with 1-MCP and $\mathrm{\gamma}$ -irradiation. Persimmon fruits with an approximate mass of $210 \pm 10 \mathrm{~g}$ and without any decay or visible physiological damage were selected and used for the following experiments.

\section{1-MCP treatment}

Prior to $\gamma$-irradiation treatment, the persimmon fruit samples were treated by 1-MCP through exposure to 1-MCP gas $(1 \mu \mathrm{L} / \mathrm{L})$ at $25^{\circ} \mathrm{C}$ for $24 \mathrm{~h}$ in a sealed polyethylene container with sufficient headspace to prevent the development of anaerobic respiration. A control sample was also prepared in polyethylene container and subjected to the same conditions in the absence of 1-MCP gas. Following treatment, the persimmon fruits were removed from the container and immediately transported for $\gamma$-irradiation treatment.

\section{Irradiation treatment}

The persimmon fruit samples were subjected to $\gamma$ -irradiation using a cobalt-60 irradiator (ACEL, MDS Nordion International Co., Ltd., Ottawa, Canada) at the Korean Atomic Energy Research Institute, Jeongeup, Korea. The absorbed doses were measured using an alanine-electron paramagnetic resonance dosimetry system with an EMS 104 EPR analyzer (Bruker Biospin, Rheinstetten, Germany). The dose rate of $\gamma$-irradiation was $0.6 \mathrm{kGy} / \mathrm{h}$ and the doses absorbed on the persimmon samples ranged from 200 to $800 \mathrm{~Gy}$. The irradiated fruit samples were then stored at $0^{\circ} \mathrm{C}$ prior to quality analysis.

\section{Firmness of persimmon fruit}

The firmness of the persimmon fruit was obtained from the maximum force at which the skinned fruit was punctured at $1.0 \mathrm{~mm} / \mathrm{s}$. This was determined at three locations along the circumference using a $5 \mathrm{~mm}$ cylindrical probe on a texture analyzer (TA-XT2, Stable Micro Systems Co., Godalming, England).

\section{Skin color}

The skin color of the fruit samples was measured at three locations on the circumference of the fruit using a Minolta Chromameter (Model CR-400, Minolta, Ramsey, NJ, USA). The measured color values of $\mathrm{L}$ (brightness), a (redness), and $b$ (yellowness) were then converted to a skin color index that is commonly employed to describe the changes in maturity of persimmon fruits from light yellow to orange/red $(17-20)$ as outlined in equation 1 :

Skin color index $=(1,000 \times a) /(\mathrm{L} \times \mathrm{b})$

(eq. 1)

\section{Respiration rate}

Two persimmon fruit samples were transferred from cold storage at $0{ }^{\circ} \mathrm{C}$ to a $1 \mathrm{~L}$ glass bottle and stored at $25^{\circ} \mathrm{C}$ for $24 \mathrm{~h}$ prior to measurement of the gas concentration. More specifically, the headspace $\mathrm{O}_{2}$ and $\mathrm{CO}_{2}$ concentrations in each bottle were measured as volume percentages at atmospheric pressure using a gas sensor (Model Check Mate 9900, PBI-Dansensor, Ringsted, Denmark).

\section{Flesh softening}

As one of the most serious physiological injuries of persimmon fruit, flesh softening was calculated as the percentage of fruit with visual softness following treatment by $\mathrm{\gamma}$-irradiation and 1-MCP.

\section{Statistical analysis}

The firmness and gas concentration data obtained as described above were statistically analyzed using analysis of variance (ANOVA). The Statistical Package for the Social 
Sciences (SPSS, Version 22.0, SPSS Inc., Chicago, IL, USA) was used for analysis, and Duncan's multiple range tests were employed to determine any significant differences $(p<0.05)$ in the various groups.

\section{Results and discussion}

Effect of $\mathrm{\gamma}$-irradiation dose on the fruit firmness

Although the use of high doses of $\gamma$-irradiation can annihilate harmful insects, they may also result in a deterioration of the quality of persimmon fruit. For example, the firmness of persimmon fruit can be severely affected by $\gamma$-irradiation. Thus, Fig. 1 shows how firmness of persimmon fruits varied over the period of the retail display at $25^{\circ} \mathrm{C}$ following $\mathrm{x}$-irradiation treatment at 0,400 , and $800 \mathrm{~Gy}$ and cold storage at $0^{\circ} \mathrm{C}$ for 60 day. As indicated, the fruit firmness decreased gradually at $25^{\circ} \mathrm{C}$ over the initial 2 day, after which time it decreased rapidly from $15-29 \mathrm{~N}$ to $<5 \mathrm{~N}$ over the following 3 day at $25^{\circ} \mathrm{C}$, to the extent that the resulting fruits were not of a suitable quality for sale. For the control sample (i.e., non-irradiated persimmon fruits, $0 \mathrm{~Gy}$ ), the firmness did not decrease significantly ( $>0.05)$ until after 1 day at $25^{\circ} \mathrm{C}$, but significant $(\mathrm{p}<0.05)$ decreases to 12.1 and $85.9 \%$ were observed after 2 and 4 day, respectively. In contrast, the firmness of the $y$-irradiated persimmon fruit samples decreased significantly $(p<0.05)$ between 0 and 2 day upon increasing the irradiation dose (day $0,0 \mathrm{~Gy}=20.6 \mathrm{~N}, 400$ $\mathrm{Gy}=18.9 \mathrm{~N}, 800 \mathrm{~Gy}=15.7 \mathrm{~N}$; day $2,0 \mathrm{~Gy}=18.1 \mathrm{~N}, 400$ $\mathrm{Gy}=14.6 \mathrm{~N}, 800 \mathrm{~Gy}=13.2 \mathrm{~N}$ ). Although the firmness

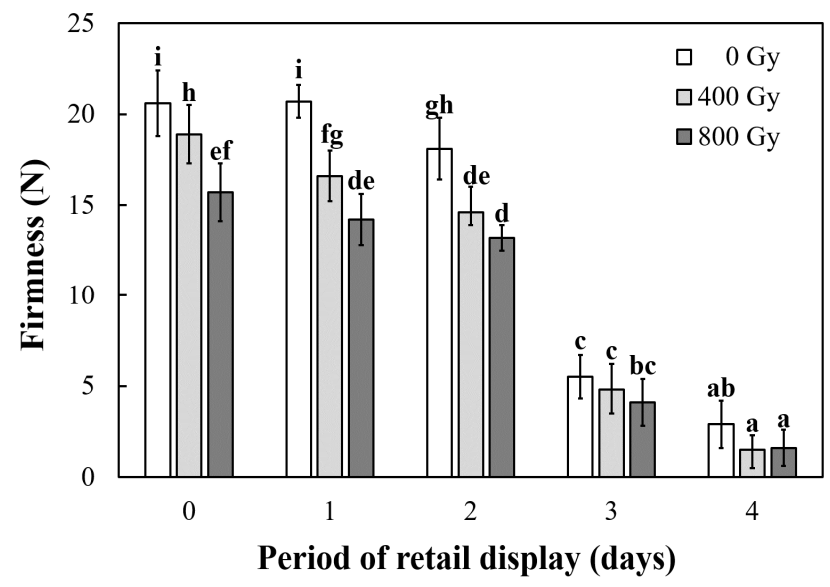

Fig. 1. Effect of $\mathrm{\gamma}$-irradiation dose on the firmness of persimmon fruit over the indicated display periods at $25^{\circ} \mathrm{C}$ following 60 day cold storage at $0^{\circ} \mathrm{C}$.

Different letters indicate significant differences at $\mathrm{p}<0.05$ based on Duncan's multiple range test. decreased further after 3 day, this reduction was not statistically significant $(p>0.05)$ due to the degree of softening observed before this point. Although irradiation treatment has been reported to delay enzymatic activities, ripening, and the senescence of climacteric fruits (21), we expect that the reduced firmness of persimmon fruit following $\gamma$-irradiation could possibly be due to radiation injuries to the fruit, which result in the severe degradation of insoluble pectic substances to yield their soluble forms (22).

\section{Respiration rate of $\mathrm{z}$-irradiated persimmon over storage time}

The respiration rate of $\gamma$-irradiated persimmon fruit was expressed in terms of the $\mathrm{CO}_{2}$ production and the $\mathrm{O}_{2}$ consumption. Thus, Fig. 2 shows the $\mathrm{CO}_{2}$ and $\mathrm{O}_{2}$ concentrations of the $\mathrm{\gamma}$-irradiated samples both before and after storage at $0^{\circ} \mathrm{C}$ for 90 day. More specifically, the $\mathrm{CO}_{2}$ gas concentration at day 0 following $\gamma$-irradiation treatment
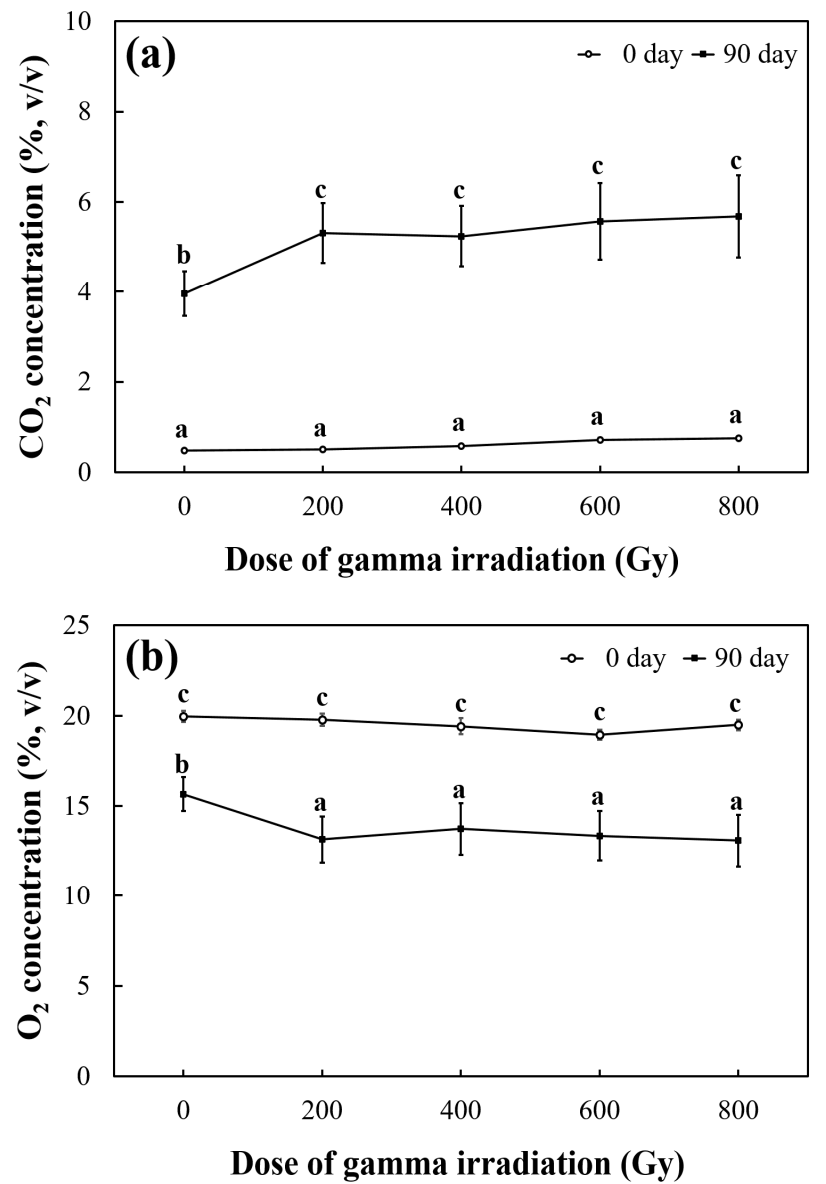

Fig. 2. Gas compositions of the $\mathrm{y}$-irradiated persimmon samples both before and after storage at $0^{\circ} \mathrm{C}$ for 90 day.

Different letters indicate significant differences at $\mathrm{p}<0.05$ based on Duncan's multiple 
range test.

ranged from 0.48 to $0.75 \%(\mathrm{v} / \mathrm{v})$, but was not statistically significant $(\mathrm{p}>0.05)$. However, for the persimmon samples stored at $0^{\circ} \mathrm{C}$ for 90 day following $\gamma$-irradiation, the $\mathrm{CO}_{2}$ concentration increased significantly $(\mathrm{p}<0.05)$ from $3.96 \%$ (v/v) for the control (non-irradiated) sample to 5.31 and $5.68 \%$ (v/v) for those irradiated at 200 and $800 \mathrm{~Gy}$, respectively, thereby indicating that the increase between different irradiation doses was not significant. A similar trend was observed for $\mathrm{O}_{2}$ consumption. In this case, at day 0 , the $\mathrm{O}_{2}$ concentration of the non-irradiated sample was $19.95 \%(\mathrm{v} / \mathrm{v})$, and no significant $(\mathrm{p}>0.05)$ change was observed following $\gamma$-irradiation treatment up to $800 \mathrm{~Gy}$. However, the $\mathrm{O}_{2}$ concentration of the irradiated sample stored at $0^{\circ} \mathrm{C}$ for 90 day decreased significantly $(\mathrm{p}<0.05)$ from $15.66 \%(\mathrm{v} / \mathrm{v})$ for the control to $13.08 \%(\mathrm{v} / \mathrm{v})$ for the sample irradiated at 800 Gy. These results indicate that the persimmon respiration rate was greatly affected by $\gamma$-irradiation, but that no significant $(p>0.05)$ difference was observed between irradiation doses. Indeed, it has been reported that harvested fresh fruits and vegetables are highly sensitive to various stresses, including wounding, bruising, and other types of physical damages (e.g., irradiation), where an increased respiration rate and ethylene production are among the general responses of fresh fruits and vegetables to these stresses (21).

\section{Effect of 1-MCP treatment on the fruit firmness}

To reduce the deterioration of persimmon fruits upon treatment with $\mathrm{y}$-irradiation, 1-MCP was also employed for sample treatment. As it is commonly known, fruit softening of persimmon can be slowed upon storage at cold temperatures due to inhibited ethylene production. Indeed, as a natural plant hormone, ethylene promote the ripening of fruits (23). The harvested persimmon samples were thus subjected to 1-MCP treatment prior to $\gamma$-irradiation, and Fig. 3 indicates how the firmness of the persimmon fruit varied upon display at $25^{\circ} \mathrm{C}$ following irradiation and subsequent cold storage at $0^{\circ} \mathrm{C}$ for 90 day both with and without 1-MCP treatment. As shown in Fig. 3a, in the absence of 1-MCP treatment, the fruit firmness decreased over the display period and upon increasing the irradiation dosage. More specifically, after $1 \mathrm{~d}$, the firmness significantly $(\mathrm{p}<0.05)$ decreased from $18.9 \mathrm{~N}$ for $200 \mathrm{~Gy}$ to $13.8 \mathrm{~N}$ for $800 \mathrm{~Gy}$ irradiation, and after 3 day, the firmness was $<1 \mathrm{~N}$ for all conditions. However, the effect of 1-MCP on the firmness of the persimmon fruit samples was significant. In this case (see Fig. 3b), the firmness of the control (non-irradiated) sample decreased slightly from
$23.9 \mathrm{~N}$ on day 0 to $20.0 \mathrm{~N}$ on 4 day, and this decrease was more pronounced at higher irradiation doses (after 3 day, firmness decreases of approximately $20,46,63$, and $71 \%$ were observed for irradiation at 200, 400, 600, and $800 \mathrm{~Gy}$ ). Interestingly, following pre-treatment with 1-MCP and irradiation below $400 \mathrm{~Gy}$, the firmness of the fruit samples remained above $10 \mathrm{~N}$. These results indicated that 1-MCP treatment could minimize the loss of fruit firmness included by $\gamma$-irradiation treatment. Indeed, Fan et al. (24) showed similar results for the irradiation of 'Gala' apples following 1-MCP treatment.
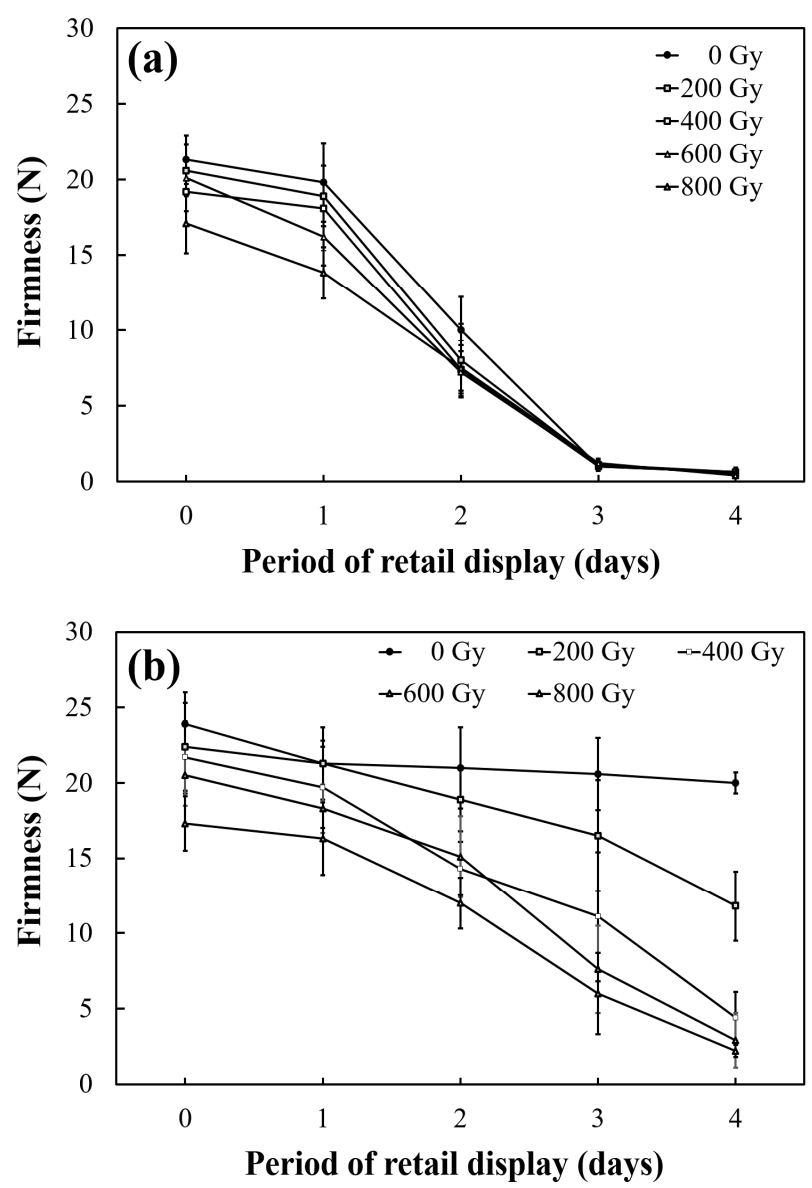

Fig. 3. Firmness of the $\mathrm{\gamma}$-irradiated persimmon samples over the specified display periods following storage at $0^{\circ} \mathrm{C}$ for 90 day: (a) without and (b) with 1-MCP treatment.

\section{Effect of 1-MCP treatment on the color index}

Fig. 4 shows color indices of the 1-MCP-treated non-treated persimmon samples over the $25^{\circ} \mathrm{C}$ display period following irradiation and subsequent cold storage at $0^{\circ} \mathrm{C}$ for 90 day. As indicated, the color indices increased over 3 day, but no significant increase was observed for the samples treated with 1-MCP. It should be noted here that a higher color index 
indicates ripening of the persimmon fruit and an increase in the a (redness) value. No significant differences were observed upon varying the irradiation dose for either set of samples.
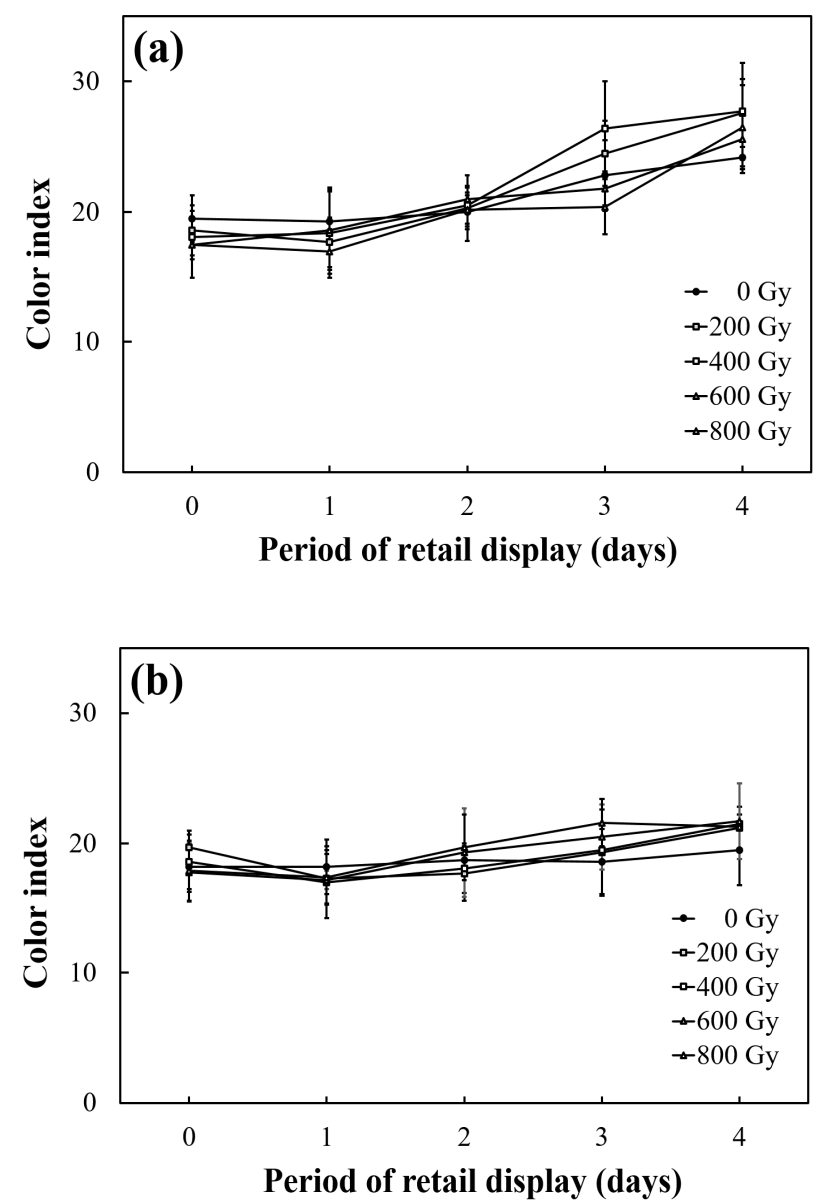

Fig. 4. Color indices of the $\mathrm{\gamma}$-irradiated persimmon fruits over the indicated display periods following storage at $0^{\circ} \mathrm{C}$ for 90 day: (a) without and (b) with 1-MCP treatment.

\section{Effect of 1-MCP treatment on flesh softening}

Flesh softening is the main injury to persimmon fruit that is responsible for drop in its commodity value. As expected, $\gamma$-irradiation dramatically increased flesh softening over the retail display time examined herein. Although the dose of $\gamma$-irradiation employed also affected flesh softening, all samples exhibited this injury following display for 4 day at $25^{\circ} \mathrm{C}$. However, we found that 1-MCP treatment dramatically reduced flesh softening from 100 to $40 \%$ (on day 4) even in the samples treated with high doses (i.e., $800 \mathrm{~Gy}$ ) of $\gamma$ -irradiation. Indeed, it was previously reported that the softening of persimmon fruit was inhibited until after 15 day following treatment with $100 \mathrm{~nL} / \mathrm{L} 1-\mathrm{MCP}$ (25). We therefore expect that 1-MCP prevents flesh softening due to the delayed pre-climacteric stage and the high affinity of 1-MCP towards the ethylene receptors of persimmon (25).
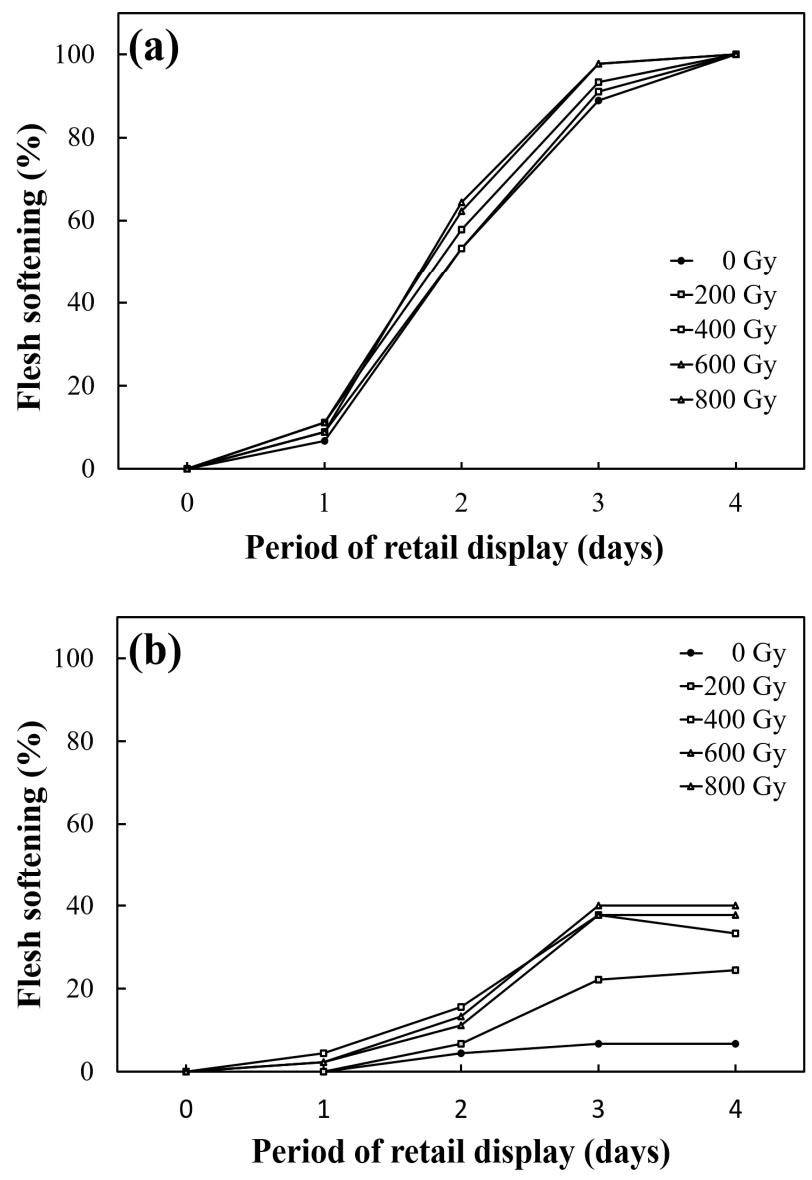

Fig. 5. Flesh softening of the $\mathrm{\gamma}$-irradiated persimmon fruit samples over the indicated display periods following storage at $0{ }^{\circ} \mathrm{C}$ for 90 day: (a) without and (b) with 1-MCP treatment.

\section{Acknowledgment}

This work was carried out with the support of the 'Cooperative Research Program for Agriculture Science \& Technology Development' (Project No. PJ0135532018) of the Rural Development Administration, Republic of Korea.

\section{References}

1. Dentener PR, Alexander SM, Lester PJ, Petra RJ, Maindonald JH, McDonald RM (1996) Hot air treatment for disinfestation of lightbrown apple moth and longtailed mealy bug on persimmons. Postharvest Biol Technol, 8, 
143-152

2. Heather NW, Hallman GJ (2008) Pest management and phytosanitary trade barriers. CABI International, Wallingford, UK, p 111-185

3. Fields PG, White NDG (2002) Alternatives to methyl bromide treatments for stored-product and quarantine insects. Annu Rev Entomol, 47, 331-359

4. UNEP (2009) Montreal protocol on substances that deplete the ozone layer. United National Environment Programme, Nairobi, Kenya, p 45-454

5. Follett PA, Weinert ED (2012) Phytosanitary irradiation of fresh tropical commodities in Hawaii: Generic treatments, commercial adoption, and current issues. Radiat Phys Chem, 81, 1064-1067

6. Hallman GJ (2011) Phytosanitary applications of irradiation. Compr Rev Food Sci Food Saf, 10, 143-151

7. Chu EH, Shin EJ, Park HJ, Jeong RD (2015) Effect of gamma irradiation and its convergent treatment for control of postharvest Botrytis cinereaof cut roses. Radiat Phys Chem, 115, 22-29

8. US FDA (2004) Irradiation in the production, processing and handling of food. Federal Register 69, US Food and Drug Administration, Silver Spring, MD, USA, p 76401-76404

9. Sisler EC, Serek M (1997) Inhibitors of ethylene responses in plants at the receptor level: Recent developments. Physiol Plant, 1000, 577-582

10. Blankenship SM, Dole JM (2003) 1-Methylcyclopropene: A review. Postharvest Biol Technol, 28, 1-25

11. Fawbush F, Nock JF, Watkins CB (2009) Antioxidant contents and activity of 1-methylcyclopropene (1-MCP)treated 'Empire' apples in air and controlled atmosphere storage. Postharvest Biol Technol, 52, 30-37

12. Li C, Shen W, Lu W, Jiang Y, Xie J, Chen J (2009) 1-MCP delayed softening and affected expression of XET and $E X P$ genes in harvested cherimoya fruit. Postharvest Biol Technol, 52, 254-259

13. Li F, Zhang X, Song B, Li J, Shang Z, Guan J (2013) Combined effects of 1-MCP and MAP on the fruit quality of pear (Pyrus bretschneideri Reld cv. Laiyang) during cold storage. Sci Hortic, 164, 544-551

14. Piriyavinit P, Ketsa S, van Doorn WG (2011) 1-MCP extends the storage and shelf life of mangosteen (Garcinia mangostana L.) fruit. Postharvest Biol Technol, 6, 15-20

15. Singh SP, Pal RK (2008) Response of climacteric-type guava (Psidium guajava L.) to postharvest treatment with 1-MCP. Postharvest Biol Technol, 47, 307-314

16. Singh SP, Singh Z (2012) Postharvest oxidative behaviour of 1-methylcyclopropene treated Japanese plums (Prunus salicina Lindell) during storage under controlled and modified atmospheres. Postharvest Biol Technol, 74, 26-35

17. Arnal L, del Rio MA (2004) Quality of persimmon fruit cv. Rojo brillante during storage at different temperatures. Spanish J Agric Res, 2, 243-247

18. Jimenez-Cuesta M, Cuquerella J, Martinez-Javega JM (1981) Determination of a color index for citrus fruit degreening. Proc Int Soc Citricult, 2, 750-753

19. Khademi O, Zamani Z, Mostofi Y, Kalantari S, Ahmadi A (2012) Extending storability of persimmon fruit cv. Karaj by postharvest application of salicylic acid. J Agric Sci Technol, 14, 1067-1074

20. Salvador A, Arnal L, Besada C, Larrea V, Quiles A, Perez-Munuera I (2007) Physiological and structural changes during ripening and deastringency treatment of persimmon fruit cv. 'Rojo Brillante'. Postharvest Biol Technol, 46, 181-188

21. Kader AA (1986) Potential applications of ionizing radiation in postharvest handling of fresh fruits and vegetables. Food Technol, 6, 117-121

22. Wani AM, Hussain PR, Meena RS, Dar MA (2008) Effect of gamma-irradiation and refrigerated storage on the improvement of quality and shelf life of pear (Pyrus communis L., cv. Bartlett/William). Radiat Phys Chem, 77, 983-989

23. Singh R, Dwivedi UN (2008) Effect of ethrel and 1-methylcyclopropene (1-MCP) on antioxidants in mango (Mangifera indica var. Dashehari) during fruit ripening. Food Chem, 111, 951-956

24. Fan X, Argenta L, Mattheis J (2001) Impact of ionizing radiation on volatile production by ripening Gala apple fruit. J Agric Food Chem, 49, 254-262

25. Harima S, Nakano R, Yamauchi S, Kitano Y, Yamamoto Y, Inaba A, Kubo Y (2003) Extending shelf-life of astringent persimmon (Diospyros kaki Thunb.) fruit by 1-MCP. Postharvest Biol Technol, 29, 318-323 